\title{
COVID-19 and the Authority of Science
}

\author{
Griffin Trotter ${ }^{1}$
}

Accepted: 24 May 2021

(c) The Author(s), under exclusive licence to Springer Nature B.V. 2021

\begin{abstract}
In an attempt to respond effectively to the COVID-19 pandemic, policy makers and scientific experts who advise them have aspired to present a unified front. Leveraging the authority of science, they have at times portrayed politically favored COVID interventions, such as lockdowns, as strongly grounded in scientific evidence-even to the point of claiming that enacting such interventions is simply a matter of "following the science." Strictly speaking, all such claims are false, since facts alone never yield moral-political conclusions. More importantly, attempts to present a unified front have led to a number of other actions and statements by scientists and policy makers that erode the authority of science. These include actions and statements that: (1) mislead the public about epidemiological matters such as mortality rates, cause of death determinations, and computerized modeling, or fail to correct mainstream media sources that interpret such concepts in misleading ways; (2) incorporate moral-political opinions into ostensible statements of fact; and (3) misrepresent or misuse scientific expertise. The fundamental thesis of the paper is not primarily that such actions and statements have proliferated during the COVID-19 epidemic (though I think they have), but rather that they are unscientific and that presenting them as science undermines the authority of science. In the moral-political realm, the great power of science and the source of its authority derives from its agnosticism about fundamental moral-political claims. Science, for instance, has no built-in presumption that we should respect life, promote freedom, or practice toleration; nor does it tell us which of these values to prioritize when values conflict. Because of this agnosticism, science is recognized across a broad diversity perspectives as morally and politically impartial, and authoritative within its proper sphere. When it is infused with partisan bias, it loses that authority.
\end{abstract}

Keywords COVID-19 $\cdot$ Scientific method $\cdot$ Media bias $\cdot$ Moral authority $\cdot$ Scientific authority $\cdot$ Consensus $\cdot$ Coronavirus $\cdot$ Science $\cdot$ Mortality rate

Griffin Trotter

griffin.trotter@gmail.com

1 Emeritus Professor, Saint Louis University, 1234 Eagle Crest Drive, Oak Harbor, WA 98277, USA 


\section{Introduction}

Pragmatist philosopher Charles Sanders Peirce is famous (or notorious) for claiming that anyone who pursues truth for some ulterior purpose-including the ulterior purpose of benefiting others-is no scientist (Peirce, 1955 [1896], p. 43). ${ }^{1}$ Though I'd argue that it is permissible, as well as inevitable, that scientists harbor motives less pristine than a singular dedication to truth, I think that the degree to which these other motives can subvert scientific progress is vastly underappreciated in our current age. It is a species of such subversions that I'll examine in this paper, namely those arising in the scientific response to the COVID-19 pandemic.

Among the many global mass casualty events ${ }^{2}$ of the past century, the current COVID-19 pandemic ranks among the worst in terms of total worldwide casualties. ${ }^{3}$ Because the window of opportunity for containing it is small, there is emphasis on quick and widely-coordinated interventions. Possible containment strategies, which depend on balancing a wide array of sometimes-conflicting values, such as civil liberties and public safety, vary almost infinitely in accordance with the nearly infinite ways of weighing proportional significance among competing values. Yet, the broad scale of the threat and the need to coordinate strategies between localities dictate that only a very limited number of strategies can be tried. Medical and political authorities across a wide diversity of communities and nations have to quickly agree to a fairly unified plan of action if they hope to optimize successes.

This need for unity has a number of important dimensions. Diplomatically, nations need to enlist the cooperation not only of allies, but optimally of all nations. Domestically, workable and effective plans need to be formulated and enacted across jurisdictions. Most importantly, the general public needs to be persuaded that these plans are legitimate- that is, that the plans reflect both proper political processes and cutting-edge science. Once a workable plan has been formulated and agreed upon by political and medical leaders, selling it to the public becomes a crucial task.

\footnotetext{
1 Albert Einstein expressed similar thoughts, writing: "For the scientist, there is only "being," but no wishing, no valuing, no good, no evil; no goal. As long as we remain within the realm of science proper, we can never meet with a sentence of the type: "Thou shalt not lie." There is something like a Puritan's restraint in the scientist who seeks truth: he keeps away from everything voluntaristic or emotional" (1950, p. 68).

2 A mass casualty event (Trotter, 2007, pp. 4-5) is an event that causes large numbers of serious casualties such that the burden on health care systems in the locality of the occurrence becomes many times greater than baseline. In a global mass casualty event, such burdens occur intercontinentally.

3 "Casualties" consist not merely of deaths, but of people seriously enough ill or injured to require medical attention. Though they can be misleading, death tolls are often used as an index to the severity of a mass casualty event. I am writing this essay in January of 2021. Total worldwide deaths attributed to COVID-19 exceed 2 million and continue to accumulate. Among pandemics that are concentrated in time and therefore not assimilated into baseline mortality, the COVID-19 pandemic is already among the worst pandemics since the 1918-1920 influenza epidemic. If the COVID-19 pandemic miraculously ended today, its global mortality rate would approach that of the "Hong Kong" flu pandemic of 1968 and the "Asian" flu pandemic of 1957, each of which killed about a million people when the world population was 45\% (1968) and 37\% (1957) what it is today (Centers for Disease Control, 2019a, b; Worldometer, 2021). Almost certainly the current COVID-19 epidemic, in terms of overall mortality, will eventually become the worst pandemic of its type since the 1918-1920 influenza epidemic, which was far worse.
} 
When public acceptance of a containment strategy is suboptimum, as it has been during the COVID-19 epidemic in the United States and many other countries, questions arise about how to approach dissenters. Coercive policies, ${ }^{4}$ which form a part of many effective mass casualty responses, become more necessary, yet also paradoxically less effective, when resistance is high. Hence, the pressure to improve public acceptance of any large-scale mass casualty plan is enormous.

In the effort to present a unified front, and thus to improve public acceptance of interventions such as social distancing, mask use, lockdown, and immunization, medical and political authorities in the United States have sometimes resorted to propagandization, where information supporting a proposed plan is vigorously cited while information detracting from it is suppressed and misleading claims are made to enhance the rationale for the plan.

As a conspicuous example, politicians and regulators in the U.S. have frequently employed the term "following the science" to describe the process through which they've decided on coercive containment measures. But, any claim that such measures are simply conclusions from science is not merely misleading; it is straightforwardly false. Science never determines what is morally or politically optimal; and it never tells us what to do. To the contrary, while science provides facts that are sometimes relevant to moral-political decisions, these decisions always hinge on moralpolitical values and on how these values are weighed and prioritized, one against the other. A reasonable person who values freedom highly and is willing to face a high degree of risk before relinquishing it, will choose a different way of responding to dangerous threats than a reasonable person who puts safety first-even when both persons recognize the same array of scientific facts. To present a single alternative as the only "scientific" approach ignores this reality. It is propaganda that misleads more than it illuminates.

Emphatically, the point here is not to defend a particular moral or political perspective. Many of the claims I criticize are claims that express views some would regard as representative of the political left. Far from reflecting an attempt to argue against left wing positions-which is beside the point for this essay-if there is a predominance of leftward claims among statements I examine it is because among the group I am examining-scholars, professionals, and others who are widely acknowledged as representing the perspective of science-most of the moral-political advocacy trends that way. Criticisms in this paper are not directed at underlying moral-political beliefs, leftward or otherwise, but rather at the manner in which such beliefs are sometimes incorporated into ostensibly scientific analyses. If I make any statement that presupposes the correctness of a particular moral-political ideology, then that statement fails of my purpose.

Likewise, in criticizing the views of persons widely acknowledged as scientific authorities or perceived as deriving their opinions from consultation with such authorities, I do not intend to imply that persons not widely recognized as scientific

\footnotetext{
${ }^{4}$ Coercion occurs if and only if "a person or group intentionally uses a credible and severe threat of harm or force to control others," a threat being "credible" when it will actually be carried out and is recognized as such by persons who are the target of coercion (Trotter, 2007, p. 8).
} 
authorities have better or more reasonable views. Because my concern is with the authority of science, my attention is directed toward those who are most widely regarded as scientific authorities.

An obvious objection to distinctions between who is widely recognized and who isn't is that the distinction is imprecise. That objection is to some extent valid. On the other hand, there are certain hallmarks of being a widely recognized scientific authority. These include: (1) holding powerful or prestigious academic, professional, or governmental positions that reflect recognition as a scientific expert; (2) publishing prolifically in peer-reviewed scientific journals; (3) being recognized by mainstream media as a scientific expert; and (4) writing commentary that is not being removed from social media or scientific websites on the basis that it is incorrect. These criteria are themselves incremental rather than discrete or hard-and-fast. But, I use them as a guide, as indeed limiting oneself to hard-and-fast distinctions would eliminate many of the most prevalent and effective distinctions that people use to make sense of the world.

In writing this paper, a far more challenging precision-problem is delineating what I mean by "the authority of science." Despite the centrality of this concept to my paper, I've elected to go with a relatively open-ended description. For purposes of the paper, "the authority of science" refers to the persuasive force of claims that are generally regarded as issuing from science. "Persuasive force" is the key concept. The persuasive force of science correlates both with (1) how likely people are to accept and trust, and hence to act upon, allegedly scientific claims made by scientific authorities (the acceptance of science); and (2) how persuasive scientific claims are in their own, scientific terms (the integrity of science). There are opinion polls recording attitudes about science, but I have little concern for measuring or stratifying public opinion beyond acknowledging that acceptance and trust are sometimes withheld. Furthermore, I am uninterested in examining, scientifically or otherwise, the contemporary psycho-social causes of mistrust of science. My emphasis is on factors that generally elicit distrust in reasonable persons. I make no claim that these are the only, or even the primary, causes of mistrust. Opinion polls are irrelevant to the matter of scientific integrity, and this is where my emphasis is directed. The primary questions I pose about the authority of science pertain to whether or not science sticks to its own domain and adheres to its own precepts.

\section{Misleading the Public About Epidemiological Matters}

On arguably the public's most avidly sought piece of information about COVID19 , namely the likelihood that someone contracting the virus will die from it, the American public was systematically and grossly misinformed during the entire first year of the pandemic - with very few objections from scientists. This was certainly the case with the Seattle Times, which reported from the early epicenter of the U.S. epidemic.

Like many other newspapers, the Times issued daily "breaking news" alerts relaying the latest COVID-19 morbidity and mortality statistics and highlighting the results of highly speculative "scientific" reports, such as computer modelling 
efforts that guessed (often very poorly) at most of the epidemiological features of the virus. ${ }^{5}$ Far less attention was given to studies that offered more modest estimates of the likely death toll. The biggest misinformation gaffe-hugely erroneous claims about the infection mortality rate made by the Seattle Times and most other mainstream newspapers-went on month after month with little visible opposition from knowledgeable reporters, public health officials, medical experts, or anyone else.

The basic malfunction in these erroneous reports hinges on the distinction between the "infection mortality rate" and the "confirmed case mortality rate." The infection mortality rate is the mortality rate for all persons contracting an infection. The confirmed case mortality rate is the mortality rate for all persons who have a serologically confirmed case of an infection. Because testing is more likely to be undertaken on sicker patients than on infected patients who have mild symptoms or no symptoms, the infection mortality rate for most viral illnesses is less by a large magnitude than the confirmed case mortality rate. This is especially true when access to testing is severely limited, as it was in the early stages of the COVID-19 pandemic. Only the sickest patients were being tested, though (as we now know) a majority of persons infected with CoV-2-19 do not have severe symptoms and do not require medical attention. It is likely that more than a third of infected persons have no symptoms at all (Oran \& Topol, 2020), and these patients were not taken into account in media estimates of the COVID-19 infection mortality rate.

While early reports in the New England Journal of Medicine and Lancet guessed at a COVID-19 infection mortality rate of "considerably less than 1\%" and " $0.66 \%$ " respectively (Fauci et al., 2020; Verity et al., 2020), the Seattle Times repeatedly reported rates in the $4 \%$ to $6 \%$ range in a periodic featured titled "Facts about novel coronavirus and how to prevent COVID-19." This series purported to address important questions about COVID-19. One of the questions was "How severe is COVID-19?" In answering, the Times conflated the confirmed case mortality rate with the infection mortality rate. For instance, on May 13, 2020, the Times claimed:

$>6 \%$ of confirmed COVID-19 patients have died globally in early May, meaning it may currently be 60 times more fatal than the seasonal flu. With many mild cases not reported, the percentage may be lower (Editors of the Seattle Times, 2020).

\footnotetext{
5 A particularly notorious example is a study from Imperial College in the U.K. that predicted 2.2 million deaths in the United States if nothing was done to contain COVID-19. The Seattle Times and virtually every other major newspaper in the country trumpeted this figure, and the study caused revisions to COVID-19 policy in both the U.S. and the U.K. (Booth, 2017). Very little attention was initially paid to the study's limitations and methodological flaws, though eventually these came to light. One of the most important limiting assumptions behind the model's 2.2 million U.S. fatality figure-that nothing would be done to contain the virus-included not only the assumption that governments would do nothing at all to intervene, but also that citizens would not alter their voluntary behavior in any relevant way-assumptions that were already moot at the time, since much was already being done and the likelihood that no citizens would alter their behavior was zero. As usual, many news media misrepresented the findings. Common Dream, a progressive online news website listed third on the University of Pennsylvania's list of 23 alternative news sources (University of Pennsylvania, 2020), featured a news report headlined “'Terrifying' New Research Warns that 2.2. Million Could Die of coronavirus in US Without Drastic Action," somehow assuming that "drastic action" is the only logical alternative to doing nothing at all.
} 
The claim that a confirmed case mortality rate of greater than $6 \%$ means that COVID-19 "may currently be 60 times more fatal than the seasonal flu" 6 is a major error founded on a fundamental epidemiological confusion. Based on the most reasonable scientific estimates at the time (which have held up well as more data has become available), the Seattle Times was consistently representing the virus as about 50 times more lethal than it actually was. Qualifying such a claim with a comment that "the percentage may be lower"-when in actuality it is nearly certain to be much lower-hardly counts as rectification.

For persons with even a passing knowledge of epidemiology, conflating the confirmed case mortality rate with the infection mortality rate is easily recognized as an error. So, how could such misinformation go uncorrected? Though some commentators with more apparent expertise than the Seattle Times sources did inform the Times that they were spreading misinformation-this advice being roundly ignored by Times editors ${ }^{7}$ - it is mysterious why no large-scale effort was made to inform the public that such estimates of COVID-19 mortality were unscientific and false. For their part, the Seattle Times and other newspapers who made the same error were either grossly incompetent or intentionally lying. By remaining silent or condoning such reporting - or perhaps even contributing to such mistakes with misleading comments made to reporters-scientists and various self-proclaimed experts failed to uphold scientific standards.

Less overtly dishonest, but still seriously misleading, is the focus on mortality rates rather than statistics such as loss of quality-adjusted-life-years (QALY), loss of disability-adjusted life years (DALY) or years of life lost (YLL) that are arguably much better indices of severity, and the failure to correct a widespread false belief that mortality rates can be precisely measured.

A ubiquitous problem with mortality rate analyses is that they assume that everyone dies of a single underlying cause and that causes can be accurately determined. Both of these assumptions are false. Except in cases of accidents and various lethal conditions that kill regardless of the presence or absence of underlying conditions,

\footnotetext{
${ }^{6}$ The infection mortality rate for the flu is believed to be about $0.1 \%$. The confirmed case mortality rate for influenza, on the other hand, is hard to come by because it is a relatively useless statistic (just as it is also a relatively useless statistic for COVID-19, despite being ubiquitously charted and cited). Nevertheless, data necessary for calculating a confirmed case mortality rate for influenza through spring of 2020 was available on the Centers for Disease Control (CDC) website (but is no longer available as I write this essay). Dividing the CDC figure for deaths from influenza by the confirmed cases of influenza yielded a rate of over $8 \%$. This statistic never made it into conversations about the relative severity of COVID-19 and influenza. The omission might be understandable given that such comparisons are likely to be misleading; but it is perplexing given the obsession in media and academic sources with citing confirmed case mortality rates. Perhaps informing the public that the confirmed case mortality rate for influenza was higher than the rate for COVID-19 didn't fit well with the message people were trying to impart.

7 I was one of the commentators who notified the Seattle Times of their error. I submitted an Op-ed to the Times that pointed it out. On March 20, 2020, I received an email from the Deputy Opinion Page Editor of the Times acknowledging receipt of my submission and rejecting it. This has been my only attempt so far to publish newspaper commentary about the misconceptions surrounding COVID-19.
} 
deaths are multifactorial. ${ }^{8}$ As any honest experienced physician would attest, causeof-death determinations are often a crapshoot-where many different factors have combined to cause a patient's demise, and one disease needs to be selected (for actuarial reasons) as the ultimate culprit. This pitfall is relevant to the COVID-19 epidemic in the United States, where a majority of its victims have been elderly and often also severely chronically ill. Merely being suspected of having COVID-19 has from an actuarial perspective often been taken as sufficient reason for attributing a death to COVID-19, though medically such reasoning makes little sense. ${ }^{9}$ The truth of the matter is that there is no "correct" number of COVID-19 deaths because it is simply not the case that each person dies from one discrete primary cause. Furthermore, even in cases where a single factor strongly predominates in causing a person's demise, medicine will frequently miss it. Much of the literature speculating that official COVID-19 mortality rates are too high or too low assumes that there is a correct rate that is just right. But such is not the case.

\footnotetext{
${ }^{8}$ In his seminal book, How We Die, Yale surgeon Sherwin Nuland addresses the multifactorial nature of the vast majority of deaths. He observes seven mechanisms that are involved in about $85 \%$ of deaths (one of these seven mechanisms is "decreased resistance to infection") and writes: "Many of those elderly who die will have several of them. And not only that; the personnel of any large hospital's intensive care unit can confirm the everyday observation that terminally ill people are not infrequently victims of all seven" (1993, p. 78). As Nuland observes, the truth about how we die is disclosed in everyday observations, but obscured by mortality statistics. Mortality statistics are organized around the false claims that everyone dies from a single primary disease entity and that no one ever dies from causes other than injury or contracting a disease that can be tabulated. He writes: "No one dies of old age, or so it would be legislated if actuaries ruled the world... In its obsessive tidiness, the Report [the U.S. Government Advance Report of Final Mortality Statistics] assigns the specific clinical category of some fatal pathology to every octo- and nonagenarian in its neat columns... Everybody is required to die of a named entity, by order not only of the Department of Health and Human Services but also of the global fiat of the World Health Organization. In thirty-five years as a licensed physician, I have never had the temerity to write "Old Age" on a death certificate, knowing that the form would be returned to me with a terse note from some official record-keeper informing me that I had broken the law. Everywhere in the world, it is illegal to die of old age" (p. 43).

9 The World Health Organization's "International Guidelines for Certification and Classification (Coding) for COVID-19 as Cause of Death" (2020) states: "A death due to COVID-19 is defined for surveillance purposes as a death resulting from a clinically compatible illness, in a probable or confirmed COVID-19 case, unless there is a clear alternative cause of death that cannot be related to COVID disease (e.g., trauma)." In other words, if something looks like a COVID-19 death (i.e., it is a death from a "clinically compatible illness"), then it should be listed as a COVID-19 death, whether or not the presence of COVID-19 has actually been serologically confirmed, unless "there is a clear alternative." Following this guidance, any patient dying from complications of a flu-like illness should be listed as a COVID-19 death (since flu-like symptoms constitute a clinically compatible symptom complex, unless there is a clear alternative, e.g., the patient is serologically positive for some other virus and negative for COVID-19). Since serological testing for other viruses, including influenza, is not routinely done, even in countries with advanced medical technology, adherence to these guidelines implies that most deaths from influenza, or other respiratory pathogens, will be recorded as deaths from COVID-19. Guidance from the CDC (2020) is far more scientifically credible (though, according to The Atlantic [Nguyen \& Schechtman, 2020], the CDC does not limit itself to death certificate data on its COVID-19 online tracker), but individual states in the U.S. have latitude to pick and choose which standard to follow, and many have followed the World Health Organization. Permutations on how a death becomes "officially" due to COVID-19 are complicated, and beyond the scope of this essay. In defense of organizations that use deaths that are presumed for some reason to be due to COVID-19 (rather than actually listed on death certificates as such), bureaucratic delays in releasing death certificate data make it difficult for them to do otherwise.
} 
Of course, the aforementioned problem also applies to more sophisticated ways of assessing disease impact. Another major problem with using mortality rates to assess the impact of diseases such as COVID-19 is more important because it is avoidable. It is the problem of assuming that all deaths are equally significant. One contributor to this problem is the implicit false premise that underlies virtually all bureaucratic attempts to tabulate causes of death-namely the claim that, were we to succeed in eradicating injuries and diseases, no one would die. All deaths are comparably tragic, if this premise is correct, because at least theoretically everyone retains a vast potential for a fulfilling future. This position flies in the face of one of the fundamental features of being an adult human being: knowledge that we will die. Physicians who doubt that cause-of-death determinations really deny such a fundamental fact should try entering "old age" or "indeterminate" as a cause of death on a death certificate. I have done so with considerable rebuke from bureaucrats and demands to enter a specific disease even if I have to make one up. No one is ever permitted to die because she has lived out her life span.

Also contributing to the assumption that all deaths should be regarded as equally significant is the egalitarian notion that being less disturbed by the deaths of older persons than by the deaths of younger persons is "ageist" and violates "intergenerational solidarity," and hence is morally objectionable. ${ }^{10}$ Whatever the merits of this position, its sentiment is offset by a stubborn conviction in the general population that dying old is better than dying young. For most people, the death of a young child is vastly more troubling than the death of an elderly person. I've seen this dynamic in my own family, where deaths of young children (e.g., one of my sisters) and of adolescents (e.g., one of my wife's cousins) have caused great suffering and lingering sadness, while deaths of very aged persons have been taken in stride and accepted as sad but inevitable features of human existence. Consolation resides in the knowledge that someone has lived a full life. Anyone who sees death in this way will view deadly events that claim the lives of young persons as prima facie more horrible than deadly events that claim primarily elderly persons, just because younger people lose so many valuable years of life. From this perspective, 40,000 people losing an average of 50 years of life in fatal auto accidents (amounting to 2 million years of life lost) is comparably as tragic as 400,000 people losing an average of 5 years of life from an infectious disease (amounting to an equal number of years of life lost). Such comparisons are absent from analyses that look only at total mortality.

\footnotetext{
10 A PubMed search for "ageism and COVID-19" on April 22, 2021 yielded 110 hits. These essays seem to share a common feature: each takes an egalitarian ethical framework as given, with no attempt to justify it or defend it against competing ethical frameworks. Since it is not my intention in this essay to undertake critical analysis of moral-political frameworks, I will not explore these essays, except to note that there are a diversity of reasonable ways of thinking about the ethics of aging that, for some reason, seem not to be represented in the scholarly literature on COVID-19.
} 
Technical papers or media accounts that assess the severity of the COVID-19 pandemic in terms of the years of life lost due to the disease are practically nonexistent. ${ }^{11}$ Thousands of analyses of QALY, DALY, and YLL are done for killers such as accidents and heart disease. ${ }^{12}$ So, why is no one doing them for COVID-19?

One obvious answer is that such analyses would detract from the message that COVID-19 is an unprecedented catastrophe. Though COVID-19 is quite devastating from the standpoint of simple mortality (as the figures cited in the introductory section of this paper attest), the enormity of its toll recedes considerably when one examines total years of lost life. Auto accidents, for instance, caused a number of lost life-years in 2020 that is comparable to life-years lost to COVID-19, ${ }^{13}$ even without adjusting for the quality of the years of life that were lost (which was certainly higher in the case of auto accidents). Unlike lives lost to COVID-19, this human toll continues year after year. And unlike lives lost to COVID-19, lives lost to auto accidents could have been almost uniformly saved by simple measures (such as decreasing the speed limits to 25 miles per hour and taking away driving privileges from persons caught driving with cell phones in their hands). I cannot determine what the immediate economic toll would be from such legal changes to automobile use, but suspect they would be less devastating to small businesses than closing them down entirely; and they would certainly allow children to attend school, compete in sports, and visit family during the holidays.

In line with the effort to catastrophize COVID-19, proclamations that it is far worse than the flu have proliferated. Certainly there are scientifically credible reasons for identifying COVID-19 as more serious than the flu-for instance, certain medical complications (such as thrombogenesis) that can complicate even initially

\footnotetext{
11 On January 31, 2021 I did a Medline search combining keyword "covid-19" and a second key word, either: (a) "quality-adjusted life years," (b) "disability-adjusted life years," or (c) "years of life lost." I received 15 hits on (a), 8 hits on (b), and 9 hits on (c), with considerable overlap, such that the total number of articles was less than 25 . Not all of these articles were available through my university library. Of the available articles, only one, a study published in the Journal of the Korean Medical Society, attempted to use one of these versions of lost life years to measure COVID-19 impact over a large geographic area (Oh et al., 2020), and there was no comparison in this study between the impact of COVID19 and the impact of diseases that kill a larger proportion of younger persons. A few articles recognized the superiority of lost years of life over simple mortality in assessing disease impact, and all of these studies were authored by economists. Two studies appeared to assess lost life years due to lockdown measures, but I was not able to access these articles and do not know if they compared the number of lost life-years that were caused by lockdowns to the number of lost life-years that were caused by the virus or would have been caused by the virus if the lockdowns were not implemented.

12 For instance, the World Health Organization uses Disability-Adjusted Life Years (DALY) to measure the "Global Burden of Disease" (GBD) and in 1990 accumulated sufficient data to publish GBD estimates for more than 100 diseases and injury types (World Health Organization, Undated). This data on GBD has been updated on several occasions, most recently for 2019 (World Health Organization, 2021). As an example of how mortality data differs from data about the burden of disease, "trachea, bronchus and lung cancers" is the highest-ranking cancer diagnosis on the list of global causes of death, ranking \#6, but doesn't make the Top 10 list for global burden of disease (no cancer diagnosis makes this list). "Road injuries," on the other hand, does not appear on the Top 10 list for global causes of death, but ranks \#6 for global burden of disease. Ranking first for global burden of disease is "Neonatal Conditions".

13 Given the lack of YLL analyses on COVID-19, "comparable" is as far as I can go on the topic.
} 
non-serious COVID-19 cases and potentially cause long-term morbidity. But, it is also true that relatively recent influenza pandemics—-such as the 1968 and the 1957 episodes-when adjusted for world population, killed at a rate similar to what we've experienced so far with COVID-19 while killing younger persons at a greater rate. The severity of COVID-19 epidemic, by most reasonable measures, is much closer to these relatively unnoticed recent epidemics than it is to the 1918-1920 influenza pandemic, to which it is frequently compared. In the year succeeding the 1918-1920 pandemic, life expectancy according to one source decreased from 51 to 39 years (Kolata, 1999, pp. 7-8). Nothing similar has happened with COVID-19.

The COVID-19 pandemic is not over. Despite the fact that immunizations are now approved and becoming increasingly more available, it is possible that it will get worse. No one can predict how the virus will mutate, though it is relatively certain that future mutations will diminish its susceptibility to current immunizations. Acknowledging such risks, even emphasizing them, is within the province of scientific medicine. But selectively to communicate only the most sensational information about COVID-19 in order to motivate citizens to comply with public health measures or produce other beneficial results, while ignoring data that would undermine the perception that the pandemic is an unprecedented catastrophe, is to choose propaganda over science.

\section{Confusing Facts and Values}

Among moral philosophers there is longstanding disagreement about the relation between facts and values. ${ }^{14}$ Though I belong to the pragmatist-postmodernist school that believes facts and values are never entirely discrete, I also believe that the distinction between facts and values is valid, and critically important in practical discourse. Indeed, I'd argue that many of the most important practical distinctions (such as between being hypertensive or normotensive, free or unfree, etc.) are non-discrete and hence to some degree arbitrary. I will forego a technical discussion of these matters in this paper, as virtually everyone, including the vast majority of moral philosophers, recognizes that practical distinctions between facts and values are valid and useful (as indeed they use them all the time).

An important aspect of scientific inquiry is that it investigates factual matters. Though factual inquiries include inquiries about morality-for instance, inquiries about which moral beliefs exist, how they are expressed, and how they are acquired-such inquiries are descriptive rather than normative. That is, they tell us about the features of moral belief and behavior, but do not tell us about which moral beliefs and behaviors we ought to have. With respect to moral or political

\footnotetext{
14 On one side are a large number of analytic philosophers who regard facts and values as entirely discrete (for instance, claiming there is an unbridgeable gap between "is" statements and "ought" statements). On the other side are pragmatists and postmodernists who think it is impossible to articulate a fact without expressing some degree of underlying valuation (for instance, claiming that a base-10 method of stating numbers reflects the value of counting in multiples corresponding to number of fingers we have on our hands).
} 
decisions - i.e., decisions about what we ought to do-science is staunchly agnostic. That is why, as I commented above, anyone who claims to be "following the science" is either confused or dishonest. In real-world decisions, no one ever simply follows the science.

The fact that science never alone determines moral-political decisions does not mean that it is irrelevant to these decisions. To the contrary, one of the great strengths of scientific knowledge is its agnosticism about fundamental moral values (though on occasion science might have something important to say about purported factual sources of particular values, such as whether or not they were endorsed by a particular historical figure). This makes science potentially appealing for persons with a wide array of diverging moral visions. Because factual matters constitute part of the basis for most practical decisions, an effective way of settling disagreements about facts can go a long way towards settling practical disagreements. Science at its best can be very effective at settling factual disagreements that have a bearing on practical matters.

A major problem with scientific rhetoric about COVID-19, as articulated by politicians, news reporters, and often by scientists themselves, is that it overstretches its boundaries by mixing in partisan valuations, about which science has little insight and no legitimate authority, with matters in which science can be highly authoritative. In other words, scientific rhetoric about COVID-19 often infuses ostensible fact-claims with an array of potentially controversial moral-political valuations. For one not antecedently affirming the same valuations, this kind of rhetoric is likely to come across as morally-politically biased and offensive to sound thinking. After being inundated, month after month, with such rhetoric (especially when it comes from alleged scientific experts) such a person is likely to conclude that "science" is no longer to be trusted.

I will examine some instances of fact-value confusion in subsequent sections of this paper. However, first I briefly describe an evidence classification scheme that I developed a little over a decade ago in my book on mass casualty medicine (Trotter, 2007, pp. 59-64). This scheme is designed to promote transparency in public decision-making, distinguishing between factual and valuational elements. For a fuller description, including a discussion of limitations and difficult cases for which the system is less than satisfactory, readers are referred to the initial exposition (Trotter, 2007, pp. 59-64).

Every guideline or action-guide in public health or other policy matters, including coercive mandates, implicitly contains both factual claims (F claims) and value claims (V claims). Guidelines and action-guides can hence be classified in accordance with the doxastic security of the respective F claims and V claims. A claim is doxastically secure when it is firmly grounded and not likely to require major revision. A claim is doxastically vulnerable when it not firmly grounded or it is very likely to require major revision.

F claims are considered "firmly grounded" when they are backed by good supporting evidence. Sometimes the supporting evidence will consist of scientific studies, but that is not always necessary. There would be good supporting evidence for the belief that the sun will rise tomorrow, for instance, even if the matter had not been studied scientifically. 
V claims, on the other hand, are grounded in values such as preferences and fundamental moral-political convictions that cannot be verified or falsified by scientific studies. V claims are considered "firmly grounded" when they reflect values that are widely shared and do not specify or balance these values in a way that is likely to be controversial (Beauchamp \& Childress, 2013, pp. 17-24).

Worthy of note is that being "firmly grounded" does not necessarily mean that a $\mathrm{V}$ claim is true; it denotes only that the claim is likely to be accepted. For this reason, a $\mathrm{V}$ claim that is secure in one jurisdiction (e.g., a Western democracy) might not be secure in another (e.g., a remote hunter-gatherer group). The doxastic security of F claims, on the other hand, does not vary appreciably between jurisdictions. Gravity, for instance, affects all persons in the same way, and a true fact-statement ${ }^{15}$ about gravity (and a true statement of the infectivity of the novel coronavirus) is as true for you as it is for me, regardless of our respective cultural orientations, our ideological beliefs, or our inclinations to accept or reject it.

The distinction between F claims and V claims, and between doxastically secure and doxastically vulnerable claims, begets the following fourfold classification scheme for action-guides:

Type I Guides (Generally Secure): F claims secure, V claims secure

Type II Guides (Factually Vulnerable): F claims vulnerable, V claims secure

Type III Guides (Normatively Vulnerable): F claims secure, V claims vulnerable

Type IV Guides (Generally Vulnerable): F claims vulnerable, V claims vulnerable

An important feature of action-guides in the early stages of a pandemic is that most of them will be Type IV guides, which is to say that they will not be firmly grounded either factually or normatively. Because the epidemiological characteristics of a new viral strain or a novel virus will at first be indeterminate, F claims will often have to be based on unsubstantiated guesses. Because action-guides have to balance values such as liberty and safety, which people prioritize in radically different ways, they will be normatively vulnerable.

Perhaps the greatest challenge for public policy, especially in the early stages of a pandemic or other relatively novel mass casualty event, is balancing clear-headedness about what is not known and what is inherently controversial with decisiveness in acting quickly and effectively enough to avert irreversible harms. A crucial part of meeting this challenge is transparency about uncertainties combined with an acknowledgment that policies might need revision when more is learned. To advertise preliminary Type IV guidance as solidly grounded in scientific evidence violates scientific standards and is likely to generate public mistrust, undermining the authority of science-even when such guidance results in beneficial outcomes.

$\overline{15}$ My claim here does not apply to token-reflexive fact statements. 


\section{Misunderstanding and Misusing Scientific Expertise}

The mainstream news media ${ }^{16}$ seems to have adopted what I'll call the "consensus" position about responding to the COVID-19 epidemic. Elements of this consensus position include: (1) the claim that the COVID-19 pandemic has produced medical harms that are unprecedented among pandemics of the modern age, ranking with serious pandemics of the past such as the 1918-1920 influenza pandemic; (2) the claim that benefits produced by COVID-19 containment measures exceed harms, including both economic harms and medical harms produced by decreased access to ordinarily available medical interventions (such as cancer screening and disease management) or by psychological effects of lockdown (such as depression and suicide); (3) the claim that recommended containment measures, such as the various state and municipal lockdowns, contact tracing, masking, and social distancing are the only reasonable response to the threat posed by COVID-19; and (4) the claim that acquisition, distribution, and administration of COVID-19 vaccines will end the pandemic.

As our discussion of epidemiological aspects of COVID-19 shows, the first claim in the consensus position is false. COVID-19 is, medically speaking, not (or at least not yet) an unprecedented catastrophe. By the most reasonable measures of severity such as lost years of life, strangely ignored not only by the news media but also by academic researchers, COVID-19 so far is comparable to influenza epidemics in 1957 and 1968, and far less severe than the 1918-1920 influenza epidemic.

The second claim is speculative and premature. Though it is plausible to believe that COVID-19 containment measures produce more benefit than harm, data are not yet in. Furthermore, even when data are fully gathered, reasonable disagreement inevitably will persist. People will still disagree about issues such as the relative value of medical gains versus lost liberties, livelihoods, opportunities, and fulfillments.

The third claim is also false. What counts as a "reasonable response" to COVID19 varies in accordance with moral-political variables. Though initial containment

\footnotetext{
16 By "mainstream news media" I identify the following: (1) major newspapers such as the New York Times and regional best-selling newspapers (such as the Seattle Times in my region), (2) major network television news, (3) major online news sites, and (4) prominent news sources (such as the Johns Hopkins University Twitter feed on COVID-19) filtered through social media such as Facebook, Twitter, and YouTube. There are certain notable limitations to my analyses of these sources. I am an avid reader of print newspapers and the bulk of my exposure to the media treatment of COVID-19 comes from reading sources such as the Wall Street Journal, the New York Times, the Washington Post, and the Seattle Times. These newspapers frequently report on things that occurred on social media. However, I have little direct exposure to social media news sources since I do not subscribe to social media. Another limitation is that I haven't watched TV news for decades. A few years ago I turned down an invitation from Fox News to appear on a panel of experts (debating some policy issue that I no longer remember). Colleagues in my department were amazed (and amused) that I had never heard of Fox News. Though I've been told that Fox News has a conservative bias, perhaps even greater than the liberal bias exhibited in other TV network news, I have little basis for evaluating such claims. I have on a few occasions watched $C N N$ and found it to exhibit such a blatant liberal bias that I wondered if it was a parody. If Fox News is even more biased than $C N N$, it must be hilarious-but to consider such shows as reliable news sources strikes me as unreasonable.
} 
measures may have been fairly reasonable from a particular moral-political perspective (I think some of them were), no particular array of interventions constitutes the only reasonable measures.

The fourth claim seems to me likely to be true (in the sense that transition from pandemic to endemic represents an end to the pandemic). However, the confidence with which it has been accepted is excessive. Throughout most of 2020, vaccines were viewed as a golden bullet that almost certainly would bring a swift end to the pandemic. Almost every time positive news about the development of a vaccine was released, the stock market surged and emphasis was laid on holding down the fort just a little longer until science saved the day. The obvious facts that the virus causing COVID-19 is an RNA virus that rapidly mutates in a manner similar to other RNA viruses such as influenza, and that vaccine-resistant strains might quickly emerge, were virtually ignored. As I write this paper, we are only a month into the preliminary vaccination effort and already several new strains that are apparently less susceptible to available vaccines have been identified and are rapidly spreading. As the survival benefits (to viruses) of being vaccine-resistant become more pronounced, we should expect that vaccine-resistant or partially vaccine-resistant strains will eventually emerge as the dominant strains.

Of concern in this paper is the degree to which the consensus position has been advertised as a conclusion of science, which it is not, and the frequency with which recognized scientific experts have colluded in this deception. In the next section, I will examine misunderstandings and misuses of scientific expertise that have occurred in the effort to pass off the consensus position as the only reasonable approach to COVID-19.

\section{Confusing Stature with Expertise}

There are no widely-employed general criteria for recognizing someone as an expert in various fields pertinent to the COVID-19 epidemic-fields such as virology, epidemiology, disaster medicine, critical care medicine, or public administration. Nevertheless, in serving as an "expert" in academic and governmental venues (e.g., testimony before U.S. Congress and for court cases, service on government task forces and committees, invited presentations at academic conferences), I've found that as a general rule one needs to have done something notable in a field-something that exhibits advanced, specialized knowledge and/or competence-before being recognized as an expert in that field. I've found also that having expertise in one field is not generally accepted as sufficient reason for being recognized as an expert in another field, even if the two fields are related. For instance, in a recent legal case while serving as an expert on emergency medicine and professional ethics, I pointed out an error in testimony by an anesthesiologist concerning management of cardiac dysrhythmias in the operating room. My expertise in emergency medicine (which involves considerable knowledge and experience in the management of cardiac dysrhythmias) was believed insufficient to qualify an opinion on the management of dysrhythmias in the operating room, so the court had to verify my testimony by consulting another anesthesiologist. 
The sort of things that might qualify one as a subject-matter expert ${ }^{17}$ include: $^{2}$ (1) doctoral and post-doctoral training in the specific subject matter (training in a related field may be relevant but isn't sufficient), or (2) numerous peer-reviewed scholarly publications in the specific subject matter, or (3) several years of experience addressing the subject matter in practical contexts. In my experience, I have rarely been solicited as an "expert" on any subject for which I do not have at least two of the above three qualifications - with the exception being solicitation from the news media, which seems very casual about soliciting me as an expert on practically any subject that is related in some way to my actual areas of expertise, so long as my testimony is interesting and fits with the narrative they seek to advance. ${ }^{18}$

The general lack of diligence employed by news media in determining who should count as an "expert" has been amplified in reporting on the COVID-19 pandemic. As a general rule, being a physician or medical scientist of high stature-for instance, being an academic dean or department chair or a high-ranking government bureaucrat in some department or agency concerned with something medical-has been deemed sufficient by media sources to qualify one as an expert on all aspects of the management of pandemics. Despite the existence of hundreds of experts who are actually qualified in various subjects pertinent to the pandemic, many of the experts featured in op-eds and news stories about the pandemic have been (if qualifications are identified at all) persons who apparently have none of the three aforementioned qualifications on the subject matter about which they have been offering opinions.

For example, in response to study outcomes that reflected the antecedently obvious fact that the actual COVID-19 infection mortality rate was probably vastly lower than what the news media was reporting, the Washington Post published an opinion piece entitled "Beware of studies claiming covid-19 death rates are smaller than expected," in which the primary author was George Q. Daley. The basic premise of the piece is expressed as follows:

\footnotetext{
17 These features of persons recognized as experts overlap considerably with previously described hallmarks of being a widely recognized scientific authority. However, my concern here is to identify some of the features that pertain when expertise is recognized in formal proceedings, such as court cases and professional committees issuing treatment guidelines, rather than features widely recognized by the public at large. Part of my concern is that criteria required in formal proceedings are not required by sources who report scientific opinions to the general public.

18 An example is the matter of a bus accident that occurred in the vicinity of a recently-opened hospital where I served as Chief of Emergency Services. Though there were numerous casualties in this accident, none were serious, and the management of these casualties was medically trivial. One of the hospital administrators, eager for positive publicity, called the news media to report we had received multiple casualties from a bus accident. Reporters approached me in the emergency department and I told them that the injuries were minor and victims required little medical attention. The next day an article ran in the city's primary newspaper about the accident. My comments did not appear (despite the fact that I was the physician who treated all the casualties). Instead, the story highlighted quotes by various physicians and department heads that were not involved in the incident-including a statement that if our hospital was not present in the immediate vicinity of the accident "a lot of people would have died." Somehow the fact that such statements were completely false bothered neither the people who made them nor the reporters who trumpeted them. Not long afterward, I quit doing interviews with the news media-much to the chagrin of marketing personnel in the various institutions where I worked.
} 
Two recent studies from California, using antibody tests designed to look for immune markers of previous infections, seem to suggest that the virus is much less deadly than many previously thought. But beware of these findings: They have not been vetted and should be recognized as such (Daly et al., 2020).

What the authors somehow neglect to mention is that the fatality rate they endorse as the best current estimate, which they describe as what "many people previously thought" prior to the California studies, was not widely endorsed by persons with actual expertise on the matter, was not itself "vetted" in the manner they demand, and was based on a major epidemiological confusion known to produce greatly exaggerated estimates of the fatality rate (see discussion above). Daley and his colleagues correctly point out several methodological limitations of the California studies, highlighting the possibility of selection bias in a sample population that was acquired on Facebook. It is indeed possible, as they imply, that people who spend a lot of time reading Facebook, and volunteer for diagnostic tests, are for whatever reason more likely to be infected with coronavirus than randomly selected persons. But, they don't mention another obvious and fundamentally important fact that the selection bias behind what they recommend as the best estimate-namely assuming that the infection fatality rate will mirror the confirmed case fatality rate-is much higher than the bias they identified in the California studies, since a selection method that includes only people with infections severe enough to evoke testing will select out infections that are more severe than a selection method (such as the one they criticize) that also includes people without symptoms sufficient to be noticed or to evoke testing.

The Washington Post piece finishes with the admonition: "Making decisions that involve human lives should be based on science, verified and vetted. In our understandable desire to return to normalcy today, we can ill afford to sacrifice our health and well-being tomorrow." There are two possible ways of interpreting this statement. First, one could conclude that the authors make two highly dubious implicit assumptions: (1) that it is important to utilize high standards of scientific evidenceexcept when conclusions support a narrative one endorses (such as the authors' endorsement of a narrative that exaggerates the infection fatality rate from COVID19), and (2) it is permissible to present false information to the public if one believes the public will benefit from being deceived. The other possibility is that the authors are simply ignorant of basic statistical and epidemiological methods.

Though one need not be an expert to recognize the many errors in this editorial, it is notable that Daly has no identified expertise in pandemics, epidemiology, or mass casualty medicine. Pertaining to his credentials, The Washington Post mentions only that he is dean of the Harvard Medical School. Likewise, none of the co-authors has any relevant expertise that is cited, beyond merely being professors and/or researchers at Harvard. The Post seems to have assumed that Daly's stature as a medical school dean was sufficient to qualify him as an expert on the evaluation of pandemics. This is an extremely low bar. It is one of many examples where the news media has highlighted the opinions of high-ranking bureaucrats, physicians, researchers and industry leaders who demonstrate little or no expertise on the subject matter for which they are taken to be experts. 
The Washington Post would be justified, to some extent, in replying that it is a responsibility of people who are solicited as experts to self-identify their own limitations when they are solicited for opinions about matters for which they lack sufficient knowledge or experience. This point is valid and underscores the fact that medical professionals and scientists themselves bear significant responsibility for the news media's misrepresentation of facts about COVID-19. The responsibility borne by self-proclaimed experts is magnified when they offer unsolicited opinions, such as when they submit an unsolicited op-ed piece to a newspaper.

\section{Confusing Expertise with Moral Authority}

A common error in commentary about COVID-19 is the assumption that persons who are well-informed on factual matters pertinent to COVID-19 are on that basis also qualified to determine what ought to be done about COVID-19. This error represents a fundamental confusion about the fact-value distinction, discussed above. Though it is reasonable to hold that being well-informed about factual matters is a necessary condition for authority on what ought to be done, it is not reasonable to hold that it is sufficient.

It is nearly impossible to find anything on the topic of COVID-19, except dry reports of laboratory investigations in technical journals, that does not manifest this error. Factual claims about the effectiveness of masking, social distancing, contact tracing, and lockdowns are regularly followed by conclusions that these are things that we should do. Even opposition to such interventions sometimes assumes that facts are determinative and that the only effective way to oppose something is to exhibit that it is based on faulty science. But on most controversies about what to do about COVID-19, pertinent values are comparably important to pertinent facts. And being an expert on the latter does not qualify one as an authority on the former.

The unscientific tendency to mistake political advocacy for scientific analysis is not merely an error of journalists who report on medicine and science. It is actively perpetrated by many scientists themselves. For instance, several hundred public health professionals and infectious disease professionals, ${ }^{19}$ along with "community stakeholders" who apparently are not health professionals, in June 2020 signed and released a document titled: "Open letter advocating for an anti-racist public health response to demonstrations against systemic injustice occurring during the COVID19 pandemic" (Anonymous, 2020). The letter does not list its authors, but Mallory Simon of CNN reports that many of the authors are from the Division of Allergy and Infectious Diseases at the University of Washington (Simon, 2020). Notably, this university is located near the Capital Hill neighborhood in Seattle, where antiracist protestors at about the same time established a zone they regarded as politically independent from the governments of the U.S., the state of Washington, and the city of Seattle.

\footnotetext{
${ }^{19}$ Many but not all of the signatories to this letter were public health professionals or infectious disease professionals, as the letter claims and the credentials of many signatories attest.
} 
The letter makes a number of ostensibly scientific claims. Evidence is offered for some of these claims, but none of this evidence is scientifically compelling. For example, the letter claims that: (1) "systemic racism" and "white supremacy" are pervasive in the United States; and (2) that anti-racist demonstrations "that call attention to the pervasive lethal force of white supremacy" are "vital to the national public health" (Anonymous, 2020). With regard to the first claim, the terms "systemic racism" and "white supremacy" are not defined. "White supremacy," as most dictionaries recognize, is the doctrine "that the white race is inherently superior to other races and that white people should have control over people of other races" (Merriam Webster, 2021). Though motives and private beliefs often differ from public pronouncements, few if any elected U.S. officials support a doctrine of white supremacy, and when asked virtually all of them have openly repudiated white supremacy.

In claiming that a view that is widely repudiated is actually pervasive, clarity in defining the view and diligence in analyzing evidence are arguably quite crucial. But, the letter's analysis is superficial and at times deeply unscientific. For instance, in support of their claim that white supremacy is pervasive, the authors offer as their first piece of evidence: "Black people are twice as likely to be killed by police as white people" (Anonymous, 2020). This datum does not provide evidence that black people are unfairly targeted in police shootings, nor evidence that unfair targeting is due to the pervasiveness of white supremacy. It is probably also true that people under 30 years of age are more likely to killed by police than people over 80 years of age, but to my knowledge few are claiming that this difference demonstrates antiyouth discrimination or elder supremacism. To show evidence of police discrimination against some particular group, one would need to present comparative evidence on how often persons in that group (compared to other groups) present credible threats that might precipitate police shootings. Since presenting a credible threat is not a datum that is collected for analysis, one might need to rely on surrogate markers, i.e., factors likely to correlate with police confrontations-things such as the recorded incidence of violent crimes within a group or the tendency within a group to distrust the police. The authors provide nothing of this nature. Furthermore, even if discrimination against black persons is present in police shootings (the authors' failure to demonstrate discrimination does not constitute evidence that there is no discrimination), there are multiple possible explanations other than pervasive white supremacism for such a fact.

No evidence at all is given for the second claim, that demonstrations calling attention to white supremacy are crucial to national public health. The authors merely contrast the moral legitimacy of anti-racist demonstrations with the moral depravity of anti-lockdown demonstrations, stating that the latter "not only oppose public health interventions, but are also rooted in white nationalism and run contrary to respect for Black lives" (Anonymous, 2020) No consideration is given to the possibility that most anti-lockdown protestors actually mean what they say, namely that they are motivated primarily by perceived threats against their civil liberties and/or their impression that government officials are reacting improperly to the COVID-19 pandemic. The authors contrast the peacefulness of anti-racist demonstrations with the violence of anti-lockdown demonstrations, citing a single example of an anti-lockdown protest in 
Lansing, Michigan that featured "heavily armed and predominately white protestors" who occupied a government building (a protest in which no one was seriously injured and protestors allowed the police to take their temperatures as they entered the capital building). The fact that anti-racist protestors in Seattle had occupied a whole neighborhood, brandished weapons, evicted the police, destroyed places of business, and perpetrated numerous acts of violence went unmentioned. ${ }^{20}$

Several other scientifically invalid inferences are also made. Foremost among these is the recurring inference that differences between ethnic groups (which are something science is potentially able to measure) equate to "disparities" between ethnic groups (which are value judgments regarding the moral significance of such differences, that science cannot establish). ${ }^{21}$ The difference-disparity confusion is by no means unique to these authors. To the contrary, uncritical claims of "disparity" proliferate in public health scholarship.

The tendency among public health leaders to conflate science and moral-political advocacy is so extreme that, in at least one instance, an entire school of public health has declared itself also to be a school of social justice. At my home institution, Saint Louis University, the "School of Public Health" changed its name to the "College for Public Health and Social Justice"-despite at the time not offering a single course on distributive justice or (to my knowledge) having a single faculty member with advanced training in the subject. Because they had no qualified faculty, they approached me to teach a course on ethics in public health. However, this course was dropped on the basis that I spent too much time contrasting opposing conceptions of public health ethics, including opposing theories of justice, and I neither identified nor taught a single "right" way of thinking about these matters. They decided that a more practical way to teach public health ethics would be to rely on public health faculty to impart their own convictions on justice and public health ethics as part of the process of teaching courses in public health science. Of importance to this paper, inculcating one's moral-political beliefs is not an element of teaching scientific methods, in public health or in any other scientific field. ${ }^{22}$

\footnotetext{
${ }^{20}$ In the month following the release of the letter, six people were shot (two fatally) on a single corner of Seattle's autonomous zone. Seattle Mayor Jenny Durkan, who had supported the existence of the autonomous zone as well as the boarding-up of the police precinct ordinarily serving that area-anticipating a "summer of love"- - decided that the area needed to be reclaimed. New York Times reporter Kirk Johnson reports (2020) that efforts to reclaim the area were delayed due to the threat of conflict. By year's end, the homicide rate in Seattle was $48.57 \%$ higher than in the previous year (Craighead, 2021). Reports of violent crime were slightly lower, presumably in part because police reports of violent crimes are less likely to be filed when the police precinct has been boarded up.

21 In some contexts, "difference" and "disparity" are quite close in meaning, with "disparity" denoting any difference that is significant to the topic under analysis. An example would be: "The disparity in talent between the two teams made the outcome of the game inevitable." However, in social philosophy and public health, the significant feature at issue in "disparity" claims about differences in income, wealth, access to services, and so forth, is usually fairness. Hence, "disparity" in the social sciences and public health literature typically denotes a moral dimension, as it clearly does in the open letter.

22 Public health experts are by no means the only experts who conflate moral-political advocacy for what should be done about COVID-19 with scientific analysis of the facts about COVID-19. For an example of moral-political advocacy disguised as expert commentary in a major journal of medicine, consider a piece published in the Journal of the American Medical Association titled "Experts Discuss Covid-19:
} 
The establishment of various forms of moral authority, including political legitimacy, is an immensely controversial topic and far beyond the scope of this paper. I discuss it at length elsewhere in relation to authority problems arising in mass casualty medicine (Trotter, 2007, pp. 15-83). Rather than offering an account of the ways in which moral authority is legitimately obtained, I claim here only that the acquisition of scientific knowledge is not one of those ways. When scientists addressing the public claim or appear to claim otherwise, they undermine the authority of science on matters where it is legitimate.

\section{Confusing Expert Consensus with Scientific Evidence}

In practical matters, a consensus of experts often does constitute a warrant (and hence a form of evidence) for a hypothesis. But a practical warrant is not necessarily a scientific one. Opinion, in particular, is not a form of scientific evidence. Scientific methodology is diligent in efforts to exclude opinion because antecedent opinions can corrupt the collection and interpretation of scientific data. Opinions ideally are be based on, and subsequent to, scientific evidence, rather than an antecedent influence on the generation of scientific evidence.

As philosophically-inclined scientists such as Charles S. Peirce and Albert Einstein observe, scientific discovery typically begins with a curious observation. Something happens that seems wondrous or unexpected-eliciting the attention of scientifically-minded persons. Hypotheses are created to explain the curious observation. Some hypotheses are better than others for scientific purposes - the best ones being the ones that are most easily falsifiable or most plausible given what is already known. Hypotheses are tested, and those that survive are tested further, until better hypotheses arise. And the process never ends.

Something that both Peirce and Einstein emphasize and that echoes throughout the tomes on philosophy of science, is that scientific inquiry never reaches its ultimate conclusion; no hypothesis is ever verified to the point of epistemic certainty. Furthermore, even when a hypothesis produces psychological certainty (as did Newton's law in the minds of many 19th Century scientists and philosophers), it is likely to be false. Hence, the genuinely scientific mind is relatively refractory to fashion

\footnotetext{
Footnote 22 (continued)

Vaccine Allocation, Placebo Groups, and More" that features selected comments from experts made in interviews with JAMA Network Editor in Chief Howard Bauchner (JAMA Editors, 2020). One of the experts describes persons who complain about lockdowns as misrepresenting their own views, claiming that "what people are saying" is "I want to go back to my normal life. I don't want to be inconvenienced." Using the term "inconvenienced" to describe the loss of businesses, livelihoods and major lifestyle activities understates the magnitude of harms caused by lockdowns. More to the point, even if owning a business, having a job, experiencing youth milestones, and not being depressed really are trivial matters, some persons still honestly regard them as important. Despite my aversion to counterfactuals, I venture that if an expert trivialized anti-racist testimony in a manner similar to how this expert trivializes antilockdown testimony-for instance by claiming it is actually a simple expression of desire for special entitlements-JAMA would not select it for publication (and rightly so).
} 
and to psychological certainty, while exhibiting and cultivating curiosity even about matters that non-scientists take as settled. Such refractoriness ensures that hypotheses will continue to be generated, orthodoxies questioned, and scientific knowledge advanced.

When scientists are solicited for guidance on practical affairs, such as building bridges or formulating pandemic policy, motives contrary to curiosity and to the generation of novel hypotheses are introduced. The tendency shifts to summarizing what is currently believed by the most qualified experts; and the creative desire to articulate as many plausible hypotheses as possible gives way to a practical desire for isolating a single plausible hypothesis as the current best guess.

By its very nature, this transition threatens the integrity of science. It diminishes motives that arguably are fundamental to scientific inquiry.

The transition is also reasonable. Practical applications cannot wait until science is complete because, among other reasons, science will never be complete. People who apply science have jobs and motives that necessitate action, sometimes at the expense of inquiry. That is part of the reason why practicing physicians and medical researchers rarely manifest the hard science mentality of quantum physicists. Clinical physicians practice in an intensely social milieu, and are concerned for the well-being of individual patients for whom they assume immediate responsibility. Physician researchers typically also are clinically trained and experienced, and take on additional pressure to secure lucrative grants from governments and companies. To worry about practical matters, such as benefiting others or articulating workable hypotheses, seems quite reasonable in such circumstances, and hardly blameworthy.

The problem comes when scientists misrepresent plausible hypotheses as confirmed hypotheses or established truths. This kind of misrepresentation is a fundamental error. Practically speaking, such misrepresentations are especially acute when speculative hypotheses (however plausible) are imbedded in Type II (factually vulnerable) or Type IV (generally vulnerable) guidelines.

One of the most prevalent ways of perpetrating this misrepresentation is by imbedding it in a falsehood-namely the prevalent but false belief that that scientific consensus is a form of scientific evidence.

As noted above, in practical matters, a consensus of experts often does constitute a warrant (and hence a form of evidence) for a hypothesis. Though I've argued that the extent of this warrant tends to be greatly exaggerated, especially when the consensus in question is a consensus of bioethics experts on a moral-political hypothesis (Trotter, 2008), it is important for the purposes of this paper to acknowledge that scientific consensus can be a reasonable warrant for public acceptance of scientific hypotheses, especially when there is an urgent need for action. But, a consensus of scientific experts, however justifiable it may be in social and practical terms, is not a scientific warrant.

Scientific hypotheses are verified by experiments, not by coalescence of opinion. Something curious is observed. Multiple hypotheses are generated to explain the observation. Effects that would pertain under certain circumstances if a given hypothesis is true are calculated. These circumstances are then experimentally created or approximated, and experimental data are generated. Data are then analyzed for their conformity with, or departure from, what the hypothesis predicts. 
Conformity provides evidence that the hypothesis is true and disconformity provides evidence that the hypothesis is false. Then further experiments are conducted, including experiments by other researchers. Experiments by other researchers are needed not primarily because there is a scientific requirement for consensus, but rather because their methods of inquiry might for whatever reason (less biased, less dishonest, less affected by disruptions of experimental protocol, etc.) produce differing results.

This basic framework for generating and interpreting scientific evidence does not recognize the opinions of researchers as a form of evidence. To the contrary, it strives to eliminate opinions and perceptions from the experimental process (for instance, by procedures such as blinding). No doubt researchers' opinions play an inevitable practical role in determining which hypotheses get investigated, especially when investigations are arduous or expensive. They also are important in deciding on basic standards of experimental design and the evaluation of data that allow scientists to compare data generated by different experimenters (for instance, standards for conducting clinical trials and measuring statistical significance). But, they play no legitimate role in the investigation itself. They do not count, scientifically speaking, as evidence.

\section{Suppressing Criticisms of the Consensus Position}

As noted, people who understand and have studied scientific evidence pertaining to a factual matter are quite straightforwardly better suited to offer useful opinions about the matter than people who do not understand or have not studied the scientific evidence. Unfortunately, being well-informed about a factual matter does not automatically result in a reasonable opinion. And, reasonable opinions will themselves vary, even among the well-informed.

Disagreements from qualified experts often derive, among other things, from values and personality traits that are foreign to scientific analysis. As the history of scientific advancement repeatedly illustrates, it is far more credible, epistemically and practically, to mediate opposing opinions among scientifically qualified persons by looking at the scientific evidence they offer for their opinions than by simply going with the most popular opinion. Comparative judgments are hampered when nonconsensus positions are censored. For this reason, censorship has rarely if ever been a driving force for scientific innovation or advancement.

On December 8, 2020, Pierre Kory, MD, testified before the U.S. Senate Committee on Homeland Security and Governmental Affairs about the use of ivermectin for prevention and early treatment of COVID-19. Dr. Kory represented an alliance of critical care specialists with, according to his testimony, "almost 2000 peer-reviewed publications in the medical literature as well as over 100 years of bedside clinical experience in ICUs around the country" (Kory, 2020). He presented evidence favoring ivermectin treatment for COVID-19, as well as a protocol for its use. This evidence included: 4 prospective randomized clinical trials (RCTs) and 2 observational controlled trials (OCTs) examining its use in prevention; 3 RCTs and multiple case 
series examining its use in early treatment; and 4 RCTs and 4 OCTs examining hospital treatment.

Four months prior to Dr. Kory's testimony, in August of 2020, the FDA published an examination of ivermectin use for COVID-19. Most of the studies cited by Dr. Kory were not available at the time. Hence, the FDA looked primarily at only one study (Caly et al., 2020), and on the basis that this study was an in vitro study in which the concentration of ivermectin was tenfold higher than what would be achieved with the approved dosage of ivermectin, the FDA recommended against the use of ivermectin for COVID-19 $9^{23}$

Three days after Dr. Kory's testimony, a YouTube video of it had already attracted over a million viewers. In response, the Associated Press issued a "fact check" authored by Beatrice Dupuy on Kory's ivermectin claims (which was the first thing that appeared when I did a Google search on fact checks about ivermectin treatment of COVID-19 at about that time). Dupuy concluded that there was no evidence that ivermectin was effective for COVID-19 (Dupuy, 2020). In reaching this conclusion, she neither mentioned nor examined any of the numerous positive clinical trials cited by Kory. The only evidence she examined was the FDA report that was issued prior to circulation of the studies Kory cited, an anecdote about someone who died after ingesting a fish tank cleaner that he thought might be an appropriate substitute for medicinal chloroquine, and an undated hearsay comment by another physician that "at the moment" there was no "gold standard" study on ivermectin. Dupuy didn't mention the lack of "gold standard" studies for numerous interventions that were widely used at the time, such as civilian masking, using 6 feet as a reference point for effective social distancing, or keeping families indoors on lockdown while prohibiting numerous outdoor recreational activities; nor did it come up that in a time-compressed setting like a global pandemic caused by a novel virus the opportunities for conducting gold-standard clinical trials were sharply limited.

On January 14, 2021, the National Institutes of Health, which in August 2020 had joined the FDA in recommending against the use of ivermectin for COVID-19, changed its guidance to neutral, stating "that currently there are insufficient data to recommend either for or against the use of ivermectin for the treatment of COVID19" (National Institutes of Health, 2021). The NIH report reviewed clinical studies cited by Kory and found them to be limited by small sample sizes, variations in dosage, and various other methodological shortcomings. ${ }^{24}$ It concluded: "Results from adequately powered, well-designed, and well-conducted clinical trials are needed to

\footnotetext{
$\overline{23}$ I read an online version of this FDA report in fall of 2020, but subsequent to FDA updates on its guidance on ivermectin, that report no longer appears to be available online.

24 Though the findings in some of the ivermectin studies were impressive-as in an Argentine study (Carvallo, 2020), in which 131 health care workers received ivermectin (and carrageenan) and 98 did not, with none of the ivermectin group contracting COVID-19 and 11 in the non-ivermectin group contracting it-there were also studies in which ivermectin worsened outcomes. Data from multiple sources, multiple researchers, and much larger samples needs to be gathered before one can legitimately regard a treatment as scientifically verified, even in the face of such impressive preliminary studies. An editorial in the Wall Street Journal (Johnson, 2020) reported that 58\% of a non-ivermectin group of 400 healthcare workers in an Argentine study eventually contracted the virus, while none of 800 healthcare workers who received ivermectin contracted the virus, but I have been able to find no verification for this claim. Perhaps Johnson was referring to a different study.
} 
provide more specific, evidence-based guidance on the role of ivermectin for the treatment of COVID-19" (National Institutes of Health, 2021).

I find myself in agreement with the NIH on the matter. Their advice is cautious, as I'd argue it should be, and their evidentiary standards are fairly exacting. The history of treatment innovations that were initially promising but turned out to be worthless or even harmful is extensive. When there is little or no evidence for the effectiveness of a treatment, then it is generally reasonable to recommend against it. That is what the FDA and NIH did in August 2020. When evidence accumulates for the effectiveness of a new treatment, but this evidence is not robust, then it is reasonable to be neutral about its use (if the drug is known to be relatively safe), which is the NIH stance in the revised ivermectin guidelines. Phase 2 FDA-approved trials of ivermectin for COVID-19 are currently underway and better data about the effectiveness of ivermectin should be available soon.

In his Senate testimony (Kory, 2020), Kory identified what he believed to be "two critical deficits in our national treatment response" to the pandemic. Kory claimed: (1) that apart from early research into hydroxychloroquine, no significant efforts had been made, on a national scale, to "research the use of any other already existing, safe, low-cost therapeutic agents"; and (2) attempts to disseminate scientific information about ivermectin use in COVID-19 on social media had been censored. Kory also commented about the lack of actual clinical experts on various task forces that examine COVID-19 strategies, noting the predominance in expert task forces of "physician leaders of large health care organizations" and physicians who are primarily researchers rather than clinicians.

It is difficult for me to adequately evaluate the first of Kory's claimed critical deficits. My perception is that treatments that are likely to be profitable for pharmaceutical companies seem to get far more attention than those that are not. To a large extent, even government funding tends to be tilted toward such profitable treatments, in part because governments rely on expert advice from panels that are often composed primarily of physicians who receive payments and research contracts from major pharmaceutical companies (often these are the same "physician leaders" who chair academic departments). If there were no bias in COVID19 strategy towards exciting new treatments or available treatments that are still profitable, it would be surprising. Because the FDA and NIH tend to rely on opinions from researchers who are (or have been) financially connected to big pharma over physicians with primarily clinical experience and expertise, it seems plausible to wonder about untoward bias. In this regard, Kory's claim deserves consideration. On the other hand, my own experience in navigating the frustrating profusion of biased and misleading sources of "scientific information" about COVID-19 and other controversial issues, has led me to value these sourcesespecially the FDA - as especially reliable despite occasional lapses. The FDA has longed seemed to me to be to be a cold, relatively distant monolith churning out evaluations in accordance with rigid, dispassionate rules of evidence. I like that in a monolith. The point here, however, is not whether or not I side with 
Kory, but whether or not Kory's position is credible enough to be heard and to have his claim critically investigated. Clearly, it is.

Kory's second claim identifies a major problem, not just for Kory and his colleagues, but for all credible medical scientists who are critical of the consensus position. It is beyond my scope to examine the myriad cases of credible dissent that have been falsely discredited or censored by the mainstream media and by scientific experts engaged in propaganda for the consensus position. Instances are numerous and amply documented elsewhere. ${ }^{25}$

Shortly after NIH revised its guidelines to reflect accumulating evidence that ivermectin is effective for the treatment of COVID-19, YouTube removed its video of Dr. Kory's congressional testimony (Johnson, 2021). Evidently YouTube's censors believed themselves to be more astute on the matter than Dr. Kory and his colleagues, and also tasked themselves with determining which aspects of the democratic process should be made available to the public.

Sham "fact checks" such the Associated Press release on ivermectin, and other media efforts to highlight a favored narrative while shutting down voices critical of the consensus position are political propaganda passed off as the voice of science. As such, they undermine the authority of science.

The damage to scientific integrity is multiplied when reputable scientific journals do the censoring. To my knowledge, only the relatively soft censorship that occurs when peer reviewers transmit their non-scientific biases, or when editors informally favor publication of politically fashionable topics treated in politically fashionable terms, are operative on a large scale in reputable medical journals. Though these forms of censorship should be vigorously opposed (in some cases I think they are), they can hardly be eradicated. Directly introducing ideological bias into editorial policy, on the other hand, undermines scientific integrity in a particularly direct way, and could be eradicated.

In its endorsement of Joe Biden in the 2020 Presidential election on the basis that "our current leaders have undercut trust in science", The New England Journal of Medicine abandons scientific objectivity-failing to apprehend that the Republican administration of President Trump is not widely regarded as representative of science, and has little opportunity to undermine trust in science except among avid followers who long ago withdrew their trust (Editors of The New England Journal of Medicine, 2020, p. 1480). Certainly the many false and misleading statements by

\footnotetext{
25 Axe, Briggs, and Richards (2020, pp. 33-43) discuss numerous instances where scientific experts were excoriated by other experts for criticizing the consensus position, despite the credibility of their criticisms. They also discuss numerous instances where credible dissent was censored. With regard to the latter, Axe, Briggs, and Richards highlight the role of internet social media sources, such as Facebook, YouTube, and Google, who tended to regard political bureaucracies such as the World Health Organization as loci of the definitive "scientific" position. They discuss several cases where arguably more credible scientific sources were censored because they deviated from the WHO position. They write: "The social media giants propped up people who were on the side of a manufactured consensus, whether or not they were experts. And, they suppressed people who were on the other side, whether or not they were experts" (2020, p. 43). Notable for the purposes of my paper, are numerous instances where prominent experts colluded in such censorship. Unlike Axe, Briggs, and Richards, I make no argument about the prevalence of such episodes. Rather, I am pointing out that they occurred and claiming that such actions undermine scientific integrity.
} 
scientists themselves - some published in prestigious journals - are apt to be more damaging in the long run to the authority of science than tweets from a populist leader who is widely identified by his offhand attacks on the scientific establishment. A more plausible hypothesis would be that Trump created a wider-than-usual space for "trust" even in bad science, just because anything that opposes an incoherent rant seems scientifically credible by comparison.

Yet to their credit, neither The New England Journal of Medicine nor any other top tier medical journal has to my knowledge formally introduced ideological dogma into its peer review process. Perhaps they will resist pressure from political interest groups to do so. Becoming a political mouthpiece in such a direct way would severely undermine the authority of science. And, the precedent has already been set, as it is something that is being done in prestigious scientific journals outside medicine, such as the journal Nature Communications. The editors of the Wall Street Journal (2020) report how Nature Communications not only retracted an article on the basis that its results elicited disapproval from gender diversity advocates, but then subsequently updated its editorial policy to seek input on "broader societal implications of publishing a paper," commenting on the desirability that "the review process takes into account the dimension of potential harm" pertaining if a paper is published-as if "broader societal implications" and "the dimension of potential harm" are things that can be objectively assessed by peer reviewers, and as if what counts as a "harm" is not subject to ideological interpretations.

\section{Conclusion}

Science is a powerful tool that can be enormously useful in addressing practical issues, including moral and political controversies. In the moral-political realm, the great power of science and the source of its authority derives from its agnosticism about fundamental moral-political commitments. Science, for instance, has no builtin presumption that we should respect life, promote freedom, or practice toleration; nor does it tell us which of these values to prioritize when values conflict. Because of this agnosticism, science applies across a broad diversity of moral-political perspectives.

Disinterested science gives us important insights about the consequences of our actions, what we can expect from the natural order, and other matters relevant to practical life. Because contemporary science is expensive and typically requires funding, moral-political factors will weigh heavily on which things scientists investigate. But, so long as investigators adhere to scientific methods and are as rigorous as possible in differentiating scientific facts from moral-political values-including motives such as prestige, profit, and political achievement that generate and perpetuate it - the results of scientific studies will bear authority for persons with diverging moral-political outlooks. In this sense, science can be an incredibly powerful tool for mediating social controversies. It is limited in scope but should be authoritative on matters properly within its domain.

Public life during the COVID-19 pandemic has been inundated by scientific claims from policy makers, scientists themselves, and others. Many of these claims 
have been false or misleading, not because science is irremediably flawed, and only in part because it is irremediably limited, but primarily because scientific analysis has been corrupted in various ways by moral-political convictions. These corruptions undermine the authority of science. If science is to maintain its status as an important mediating device that is recognized by citizens with diverging values, then subverting scientific method on behalf of specific moral-political objectives, or to enhance a politically partisan narrative, even when the cause is laudable and the results salient, needs to cease. Like everything human beings find worth doing, science has its motives. When the strongest motive is truth, stripped as much as possible from moral-political commitments, then other motives are less likely to impede it—and its authority, as well as its potential for aiding humans, is likely to be enhanced.

Acknowledgements Thanks to Michael Brodrick, Abram Brummett, and two anonymous reviewers for helpful comments about this manuscript.

\section{References}

Anonymous. (2020). Open letter advocating for an anti-racist public health response to demonstrations against systemic injustice occurring during the COVID-19 pandemic. Retrieved February 6, 2021 from https://drive.google.com/file/d/1Jyfn4Wd2i6bRi12ePghMHtX3ys1b7K1A/view.

Axe, D., Briggs, W. M., \& Richards, J. W. (2020). The price of panic. Regnery.

Beauchamp, T., \& Childress, J. (2013). Principles of biomedical ethics (7th ed.). Oxford University Press.

Booth, W. (2017, March 17). A chilling scientific paper helped upend U.S. and U.K. coronavirus strategies. Seattle Times. Retrieved January 31, 2021 from https://www.seattletimes.com/nation-world/ the-chilling-scientific-paper-that-helped-upend-u-s-and-u-k-coronavirus-strategies/. This article was originally published in the Washington Post.

Caly, L., Druce, J. D., Catton, M. G., Jans, D. A., \& Wagstaff, K. M. (2020). The FDA-approved drug ivermectin inhibits the replication of SARS-Cov-2 in vitro. Antiviral Research, 178, 104787.

Carvallo, H. (2020). Usefulness of topical ivermectin and carrageenan to prevent contagion of COVID 19 (IVERCAR). Retrieved February 3, 2021 from https://clinicaltrials.gov/ct2/show/record/NCT04 425850 .

Centers for Disease Control. (2019a). 1957-1958 Pandemic (H2N2 virus). Retrieved January 20, 2021, from https://www.cdc.gov/flu/pandemic-resources/1957-1958-pandemic.html.

Centers for Disease Control. (2019b). 1968 Pandemic (H3N2 virus). Retrieved January 20, 2021, from https://www.cdc.gov/flu/pandemic-resources/1968-pandemic.html.

Centers for Disease Control. (2020). Guidance for certifying deaths due to coronavirus disease 2019 (COVID-19). Vital Statistics Reporting Guidance. Retrieved April 22, 2021, from https://www.cdc. gov/nchs/data/nvss/vsrg/vsrg03-508.pdf.

Craighead, C. (2021, January 12). Crime report: Seattle saw highest homicide number in 26 years; overall violent crimes lower. Seattle PI. Retrieved February 6, 2021 from https:/www.seattlepi.com/local/ seattlenews/article/2020-crime-Seattle-highest-homicide-rate-15864266.php

Daly, G. Q., Elledge, S., Alter, G., \& Springer, M. (2020, April 28). Beware of studies claiming covid-19 death rates are smaller than expected. Washington Post. Retrieved April 28, 2020 from https://www. washingtonpost.com/opinions/2020/04/28/beware-studies-claiming-covid-19-death-rates-are-small er-than-expected/

Dupuy, B. (2020, December 11). No evidence ivermectin is a miracle drug against COVID-19. AP News. Retrieved December 22, 2020 from https://apnews.com/article/fact-checking-afs:Content:97689 99400.

Editors of the Seattle Times. (2020, May 13). Facts about novel coronavirus and how to prevent COVID19. Seattle Times. B8.

Editors of the Wall Street Journal. (2020, December 24). Science eats its own. Wall Street Journal. A14. 
Einstein, A. (1950). Essays in physics. Philosophical Library.

Fauci, A. S., Lane, H. C., \& Redfield, R. R. (2020). Covid-19 - navigating the uncharted. New England Journal of Medicine, 382(13), 1268-1269.

Johnson, K. (2020, June 29). Another fatal shooting in Seattle's CHOP protest zone. New York Times. Retrieved February 6, 2021 from https://www.nytimes.com/2020/06/29/us/seattle-protests-CHOPCHAZ-autonomous-zone.html.

Johnson, R. (2021, February 3). YouTube cancels the U.S. Senate. Wall Street Journal. A15.

Kolata, G. (1999). Flu. Touchstone.

Kory, P. (2020, December 8). Focus on early treatment of COVID-19. Homeland Security Committee Meeting. Retrieved December 22, 2020 from https://www.hsgac.senate.gov/imo/media/doc/Testi mony-Kory-2020-12-08.pdf

Merriam Webster. (2021). White supremacy. Retrieved June 6, 2021, from https://www.merriam-webster. com/dictionary/white\%20supremacy.

National Institutes of Health. (2021, January 14). The COVID-19 treatment guidelines panel's statement on the use of ivermectin for the treatment of COVID-19. Retrieved February 3, 2021 from https:// www.covid19treatmentguidelines.nih.gov/statement-on-ivermectin/

Nguyen, Q. P., \& Schechtman, K. W. (2020, July 8). Confirmed and probable COVID-19 deaths, counted two ways. The COVID tracking project at The Atlantic. Retrieved April 22, 2021 from https://covid tracking.com/analysis-updates/confirmed-and-probable-covid-19-deaths-counted-two-ways

Oh, I., Ock, M., Jang, S. Y., Go, D. S., Kim, Y. E., Jung, Y., Kim, K. B., Park, H., Jo, M., \& Yoon, S. (2020). Years of life lost attributable to COVID-19 in high-incidence countries. Journal of Korean Medical Science, 35(32), e300.

Oran, D. P., \& Topol, E. J. (2020). The proportion of SARS-Cov-2 infections that are asymptomatic: A systemic review. Annals of Internal Medicine, 174(5), 655-662. https://doi.org/10.7326/M20-6976

Peirce, C. S. (1955 [1896]). The scientific attitude and fallibilsm, Part I. In J. Buchler (Ed.), Philosophical writings of peirce (pp. 42-54). Dover.

Simon, M. (2020). Over 1,000 health professionals sign a letter saying, Don't shut down protests using coronavirus concerns as an excuse. CNN. Retrieved February 6, 2021 from https:/www.cnn.com/ 2020/06/05/health/health-care-open-letter-protests-coronavirus-trnd/index.html

Trotter, G. (2007). The ethics of coercion in mass casualty medicine. The Johns Hopkins University Press.

Trotter, G. (2008). The illusion of legitimacy: Two assumptions that corrupt health policy deliberation. Journal of Medicine and Philosophy, 33(5), 445-460.

University of Pennsylvania. (2020, December 14). News, views, and tools for progressives. Updated December 14. Retrieved February 3, 2021 from https://www.sas.upenn.edu/ jtreat/progressive.html

Verity, R., Okell, L. C., Dorigatti, I., et al. (2020). Estimates of the severity of coronavirus disease 2019: A model-based analysis. The Lancet Infectious Diseases, 20(6), 669-677.

World Health Organization. (2020). International guidelines for certification and classification (coding) for COVID-19 as Cause of Death. Retrieved April 22, 2021, from https://www.who.int/classifica tions/icd/Guidelines_Cause_of_Death_COVID-19.pdf.

World Health Organization. (2021). Global health estimates: Life expectancy and leading causes of death and disability. Retrieved April 23, 2021, from https://www.who.int/data/gho/data/themes/mortalityand-global-health-estimates.

World Health Organization. (Undated). About the Global Burden of Disease (GBD) project. Retrieved April 23, 2021, from https://www.who.int/healthinfo/global_burden_disease/about/en/.

Worldometer. (2021). World population by year. Retrieved January 30, 2021, from https://www.world ometers.info/world-population/world-population-by-year/.

Publisher's Note Springer Nature remains neutral with regard to jurisdictional claims in published maps and institutional affiliations. 